\title{
Dynamics of giant volcanic ash clouds from supervolcanic eruptions
}

\author{
P. G. Baines ${ }^{1,2}$ and R. S. J. Sparks ${ }^{3}$
}

Received 13 September 2005; accepted 11 November 2005; published 23 December 2005.

[1] The largest explosive volcanic eruptions that have occurred on Earth generated giant ash clouds from rising plumes that spread in the stratosphere around a height of neutral buoyancy, with estimated supply rates that are in the range $10^{11}$ to $10^{13} \mathrm{~m}^{3} / \mathrm{s}$. These giant ash clouds are controlled by a balance between gravity and Coriolis forces, forming spinning bodies of nearly fixed proportions after a few hours and are initially insensitive to stratospheric winds. In contrast, volcanic plumes from eruptions with small to intermediate magnitude spread as inertial intrusions under the influence of stratospheric winds, with the Earth's rotation being unimportant. In the largest eruptions the giant spinning ash clouds typically develop diameters greater than $600 \mathrm{~km}$ and up to $6000 \mathrm{~km}$ in the most powerful supereruptions, thus explaining why areas of continental size can be covered with volcanic ash. The radial expansion and spinning velocities are calculated at tens of metres per second and increase with eruption intensity. Higher spreading velocities carry larger ash grain sizes to a given radius, so that grain size at a given distance from the source increases with eruption intensity, consistent with geological observations. Citation: Baines, P. G., and R. S. J. Sparks (2005), Dynamics of giant volcanic ash clouds from supervolcanic eruptions, Geophys. Res. Lett., 32, L24808, doi:10.1029/ 2005 GL024597.

\section{Introduction}

[2] Very large magnitude explosive eruptions have the potential for global catastrophe. Such eruptions can cover continental scale areas with volcanic ash and may cause severe environmental effects in the years and possibly decades that follow. Here we consider explosive eruptions of magnitude $M=6.5$ and above, where $M=\log _{10} m-7$ and $m$ is the mass of magma erupted in $\mathrm{kg}$. Such eruptions range from the largest magnitude eruptions of the last century, such as Mount Pinatubo in $1991(M \sim 6.5)$, to the largest explosive eruptions known, such as the eruption of Toba, Sumatra at 71 kya $(M \sim 9)$. Explosive eruptions with $M>8$ are commonly described as "super-eruptions". Here we establish that the spreading of such clouds is controlled by the Earth's rotation. The giant ash clouds can have very large horizontal dimensions, with spreading and spinning velocities exceeding typical stratospheric wind speeds. The model can explain why continents can be covered with volcanic ash, and why the grain size of the

\footnotetext{
${ }^{1}$ Department of Civil and Environmental Engineering, University of Melbourne, Melbourne, Victoria, Australia.

${ }^{2}$ School of Mathematics, University of Bristol, Bristol, UK

${ }^{3}$ Department of Earth Sciences, University of Bristol, Bristol, UK.
}

ash tends to be much coarser than in smaller magnitude explosive eruptions.

\section{Models for Large Ash Cloud Formation}

[3] In large explosive eruptions buoyant plumes can be generated as Plinian eruption columns, and as co-ignimbrite clouds formed by buoyant lift-off from the whole area of upper ash-rich regions of pyroclastic flows [Sparks et al., 1997]. On the scale of the problem, both clouds can be regarded as spreading from point sources. We model the volcanic cloud by assuming a localised constant flux source at ground level that emits a hot mixture of gas and particulate matter that rises as a turbulent plume [Sparks et al., 1997; Morton et al., 1956] to an equilibrium level in the stratosphere, where it spreads radially as a mixture of effectively uniform density. The volume of the ash cloud grows as $Q t$, where $t$ is time and $Q$ is the volume flux at the equilibrium level. $Q$ is much larger than the source flux at ground level due to entrainment and heating of air by the rising plume. In the stratified stratosphere (buoyancy frequency $N$ ), the hydrostatic pressure inside the ash cloud varies radially as $\rho_{0} N^{2} d^{2} / 8$, where $\rho_{0}$ is the density and $d$ is the vertical thickness of the cloud. This pressure initially causes the cloud to spread radially at the approximate speed $N d_{n} / 4$, where $d_{n}$ is the value of $d$ at the nose. However, as it spreads the cloud becomes increasingly influenced by the Coriolis force and rotates anticyclonically, much as a rigid body, with angular velocity $f / 2$, where $f=2 \Omega \sin ($ lat $), \Omega$ being the angular velocity of the Earth's rotation and lat the latitude of the source. Consequently, after a few hours the cloud attains cyclostrophic balance with the shape of an ellipsoid of revolution of the form

$$
d(r, t)^{2}=d_{0}(t)^{2}-\left(\frac{f r}{N}\right)^{2}
$$

where $r$ is the radial coordinate and $d_{0}(t)$ is the value of $d$ at the origin. $d_{0}(t)$ is determined by the volume of the cloud, which gives

$$
d_{0}(t)=\left(\frac{3 f^{2} Q t}{2 \pi N^{2}}\right)^{1 / 3}, \text { with radius } r_{m}=\frac{N d_{0}(t)}{f}
$$

where $d_{0}$ remains constant after the source stops and $Q$ vanishes, until other atmospheric processes degrade the cloud.

[4] This model of a spreading intrusion into a stratified environment differs in detail from the dynamics of radially spreading gravity currents in rotating systems into an homogeneous environment [Griffiths, 1986; Sparks et al., 1997; Ungarish and Huppert, 1998; Hallworth et al., 2001; Ungarish and Zemach, 2003]. The homogeneous case gives $d=d_{0}\left(1-\left(r / r_{\mathrm{m}}\right)^{2}\right)$, whereas the stratified case has $d^{2}=$ 
Table 1. A Range of Flow Conditions for Plinian Eruptions Showing Values of Magma Flow Rate Out of the Vent, Neutral Buoyancy Height and Stratospheric Inflow Rate at the Height of Neutral Buoyancy Estimated From the Models of for Volcanic Plumes

\begin{tabular}{ccc}
\hline $\begin{array}{c}\text { Magma Flow } \\
\text { Rate, } \mathrm{m}^{3} / \mathrm{s}\end{array}$ & $\begin{array}{c}\text { Neutral Buoyancy } \\
\text { Height, km }\end{array}$ & $\begin{array}{c}\text { Stratosphere Inflow } \\
\text { Rate, } Q, \mathrm{~m}^{3} / \mathrm{s}\end{array}$ \\
\hline $7 \times 10^{4}$ & 24 & $7.75 \times 10^{10}$ \\
$10^{5}$ & 30 & $2.8 \times 10^{11}$ \\
$3 \times 10^{5}$ & 36.5 & $1.67 \times 10^{12}$ \\
$10^{6}$ & 45 & $10^{13}$ \\
\hline
\end{tabular}

$d_{0}^{2}\left(1-\left(r / r_{\mathrm{m}}\right)^{2}\right)$. These flows are potentially unstable to baroclinic disturbances, which may cause the cloud to break up into eddies [Griffiths and Linden, 1981, 1985]. However, such instabilities take several days to develop, which we show a posteriori is significantly longer than the processes described here.

[5] In a mean wind $U$, while the eruption continues, the rising plume feeds the cloud and maintains its position relative to the source provided that $U<N d_{0} / 4$. Excluding high latitudes in the winter hemisphere, mean stratospheric winds are typically of order $10 \mathrm{~m} \mathrm{~s}^{-1}$, from east or west. The wind compresses the cloud on the upwind side and elongates it on the downwind side through the internal pressure $\rho_{0}\left(N^{2} d^{2} / 8-U^{2} \cos \theta / 2\right)$, where $\theta$ is the angle relative to the direction of the wind. The external flow mostly passes horizontally around the cloud, except for the regions within a height of $U / N$ of the top and bottom, where it passes over and under it [Baines, 1995]. Internally, the cloud rotates with the same angular velocity as without wind, but an additional internal circulation exists to accommodate the non-rotating non-axisymmetric boundary shape. A separated turbulent wake, dominated by environmental air mixed with fluid from the ash cloud, is expected. Ash clouds produced by a single rapid lift-off from large coignimbrite eruptions have similar properties, and are not affected by a mean wind other than being advected by it.

\section{Application to Realistic Eruptions}

[6] Based on geological and modelling studies we estimate the range of interest for the volumetric flux of dense magma to be $5 \times 10^{4} \mathrm{~m}^{3} / \mathrm{s}$ to $10^{6} \mathrm{~m}^{3} / \mathrm{s}$ for Plinian eruptions. We used the model of Woods [1988] to estimate the neutral buoyancy height as a function of magma flux and values of $Q$ at this height, with representative values given in Table 1 . For co-ignimbrite ash clouds we assume that pyroclastic flows are emplaced over circular areas with diameters of 60 , 100 and $140 \mathrm{~km}$ to represent a range of intensities and magnitudes. We assume that $30 \%$ of the erupted mass is lofted to form a co-ignimbrite plume over the affected area [Sparks and Walker, 1977] and that the co-ignimbrite ash clouds have thicknesses of $1,1.66$ and $2.33 \mathrm{~km}$ respectively, with a density equal to the atmosphere at the mid-height at the moment of lofting. With these assumptions we calculate the total mass of ash lofted and use the ash cloud model of Woods and Kienle [Sparks et al., 1997; Woods and Kienle, 1994] to estimate the neutral buoyancy height. We then assume that a major ignimbrite eruption consists of many individual emplacement units each emplaced over a time scale of $10^{3}$ seconds. Thus the giant cloud is fed by numerous lofting clouds over time scales $\gg 10^{3}$ seconds, so that a time-averaged value of $Q$ from a quasi-steady supply can be calculated. Table 2 gives the eruption parameters of the three cases considered with values of $Q$ in the range $5 \times 10^{10}$ to $10^{13} \mathrm{~m}^{3} / \mathrm{s}$. Magma supply rates can exceed $10^{7} \mathrm{~m}^{3} / \mathrm{s}$.

[7] For application of the theory we choose $f=7.25 \times$ $10^{-5}$ radian $^{-1}$ for a source at $30^{\circ}$ latitude, and $N=2.10^{-2}$ radian $\mathrm{s}^{-1}$. A characteristic cloud dimension is identified at which the rotation velocity equals the expansion velocity and the cloud becomes dominated by rotation. At earlier stages the cloud spreads as a gravity-driven intrusion [Sparks et al., 1997; Woods and Kienle, 1994] and so equations 1 and 2 cannot be used to estimate the total time of emplacement accurately. Figures 1 and 2 show calculations of expansion velocity, rotation velocity and erupted volume as functions of cloud diameter for Plinian and co-ignimbrite clouds respectively. In the calculations we estimate the magnitude of the eruption from magma flux and time.

[8] The calculations confirm that only explosive eruptions of magnitude 6.5 and above develop giant clouds a few thousand kilometres in diameter where rotational effects dominate. Mount Pinatubo in 1991 falls at the lower end of this magnitude range. The cloud for Pinatubo (magma flux $\sim 7 \times 10^{4} \mathrm{~m}^{3} / \mathrm{s}$ and stratospheric flow rate $\sim 5 \times 10^{10} \mathrm{~m}^{3} / \mathrm{s}$ ) [Koyaguchi, 1994] behaved like a gravitydriven intrusion during its initial expansion [Holasek et al., 1996], reaching a diameter of $1200 \mathrm{~km}$ after $4 \times 10^{4}$ seconds. Rotational waves were observed [Holasek et al., 1996] at a diameter of $800 \mathrm{~km}$ in qualitative agreement with our model (see Figures 1a and 2a). Above a magnitude of 6.5 the clouds have dimensions from several hundred kilometres to a few thousand kilometres in the largest magnitude cases. Beyond the threshold diameter the radial expansion speeds are commonly larger than typical stratospheric wind speeds but reduce to low values as the spin velocities increase with size; the cloud dimensions become constrained by the Earth's rotation. To a first order these clouds expand in all directions. Their shape is affected by the wind to a limited degree, noting that in the cases shown in Tables 1 and $2 U \sim$

Table 2. Three Representative Eruptions of Co-Ignimbrite Clouds From Ash-Flows, Lifting Off From Circular Areas With Diameters of 60, 100 and $140 \mathrm{~km}^{\mathrm{a}}$

\begin{tabular}{ccccc}
\hline $\begin{array}{c}\text { Magma Flow } \\
\text { Rate, } \mathrm{m}^{3} / \mathrm{s}\end{array}$ & $\begin{array}{c}\text { Mass of Ash in One } \\
\text { Co-Ignimbrite Plume, kg }\end{array}$ & $\begin{array}{c}\text { Neutral Buoyancy } \\
\text { Height, km }\end{array}$ & $\begin{array}{c}\text { Stratospheric Inflow } \\
\text { Rate, } Q, \mathrm{~m}^{3} / \mathrm{s}\end{array}$ & $\begin{array}{c}\text { Assumed Ash Cloud } \\
\text { Depth at Lift-Off, km }\end{array}$ \\
\hline $1.45 \times 10^{6}$ & $10^{12}$ & 27.2 & $7.35 \times 10^{10}$ & 1 \\
$6.38 \times 10^{6}$ & $4.4 \times 10^{12}$ & 34.0 & $7.49 \times 10^{11}$ & 1.66 \\
$1.66 \times 10^{7}$ & $1.15 \times 10^{13}$ & 38.3 & $3.29 \times 10^{12}$ & 2.33 \\
\hline
\end{tabular}

${ }^{\text {a }}$ The table lists the time-averaged flux of magma that includes both the ash flow and the co-ignimbrite cloud and assumes that the latter cloud contains $30 \%$ of the mass erupted. The neutral buoyancy cloud height is estimated from the models of Woods and Kienle [1994] that were further developed by Sparks et al. [1997]. The assumed depth of the ash cloud at lift-off is also listed. 


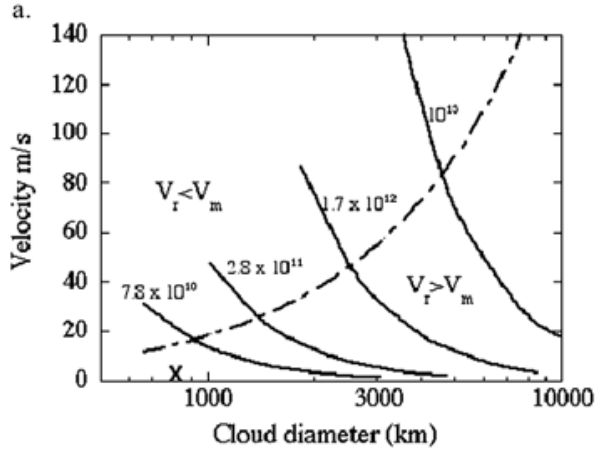

Figure 1

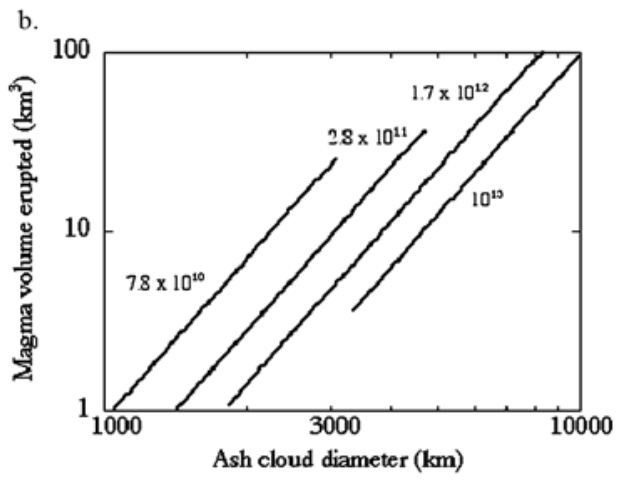

Figure 2

Figure 1. (a) Radial expansion velocity (solid curves) and rotational velocity at outer edge (dashed curve) are plotted against cloud diameter for different values of stratospheric inflow rate, $Q \mathrm{~m}^{3} / \mathrm{s}$, and neutral buoyancy height in the case of Plinian eruptions (see Table 1). The dashed curve also defines the distances at which the rotational and radial velocities are equal. Rotation effects are expected to be dominant to the right of this curve $\left(\mathrm{V}_{\mathrm{r}}>\mathrm{V}_{\mathrm{m}}\right)$. $\mathrm{X}$ marks the approximate conditions at which rotational effects can be observed in satellite images of the giant cloud of Mount Pinatubo in 1991 [Holasek et al., 1996]. (b) Theoretical erupted magma volume $\left(\mathrm{km}^{3}\right)$ plotted against ash cloud diameter for different stratospheric inflow rates in Plinian eruptions (see Table 1).

$N d_{0} / 4$ or $U<N d_{0} / 4$, for $U \sim 10 \mathrm{~m} / \mathrm{s}$. Thus they can cover much larger continental sized areas than ash plumes from weaker eruptions that are determined principally by wind dispersal from a point source.

[9] These giant clouds disperse coarse ash over large areas. The grain size and thickness of ash at a given distance from the volcano will increase with eruption intensity and magnitude respectively. The e-folding diameter of ash grain size in a giant cloud scales as $2\left[Q / \pi v_{\mathrm{t}}\right]^{1 / 2}$ where $v_{\mathrm{t}}$ is the terminal velocity of the ash particle [Sparks et al., 1991]. For example, consider particles of diameter 250 and $125 \mu \mathrm{m}$ in an ash cloud at $30 \mathrm{~km}$ injection height with terminal velocities of 2 and $0.5 \mathrm{~m} / \mathrm{s}$ respectively. Figure 3 a shows data after Ninkovich et al. [1978] for the eruptions of Santorini $(M \sim 6.9)$, Campanian ignimbrite $(M \sim 7.7)$ and Toba $(M \sim 9.0)$. The observation that grain size increases with eruption magnitude implies that intensity correlates with magnitude. This correlation is implicit in our dynamical models for both Plinian and co-ignimbrite clouds (Tables 1 and 2) and is consistent with the correlation found by Carey and Sigurdsson [1989] from reconstruction of palaeo-eruptions. Figure $3 \mathrm{~b}$ shows the e-folding diameter for particles with diameters 250 and $125 \mu \mathrm{m}$ plotted as a function of the eruption intensity represented as the stratospheric flow rate. Estimated flow rates for Santorini, Campanian and Toba eruptions that are consistent with the data in Figure $3 \mathrm{a}$ are only indicative, but are sufficient to support the hypothesis that eruption intensity increases with eruption magnitude. Figure $3 \mathrm{~b}$ also demonstrates that giant clouds of a few thousand of kilometres diameter are required to explain the observed distribution of volcanic ash from super-eruptions.

\section{Summary and Conclusions}

[10] Hence a dynamic model of ash clouds from very large magnitude eruptions shows that rotational effects become dominant for eruptions that have magnitude much greater than about $M \sim 6.5$. The clouds expand to diameters
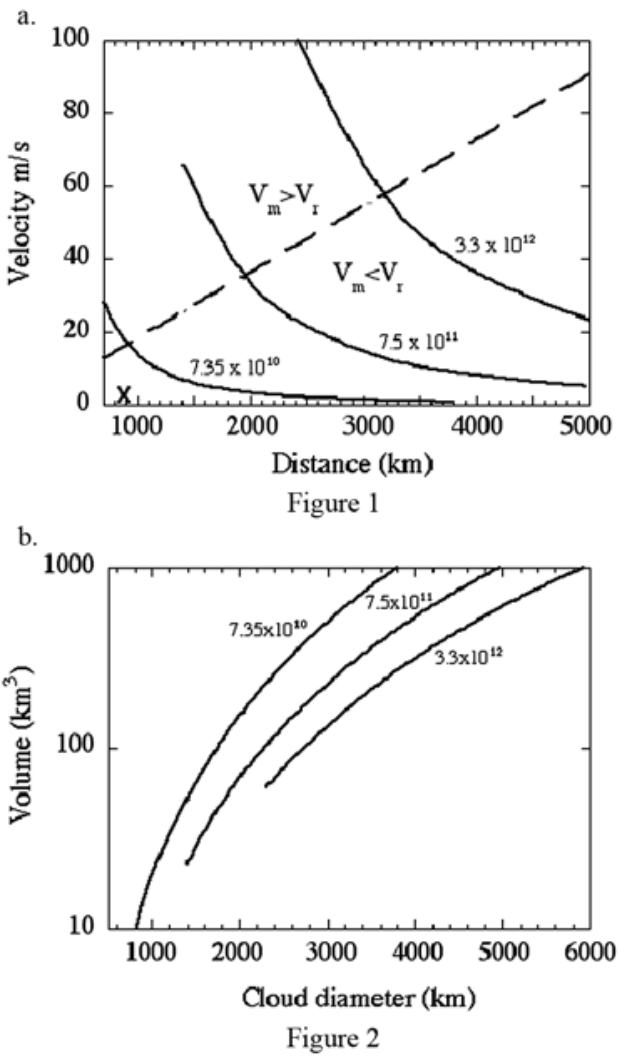

Figure 2. (a) Radial expansion velocity (solid curves) and rotational velocity (dashed curve) are plotted against cloud diameter for different values of stratospheric flow rate $Q \mathrm{~m}^{3} / \mathrm{s}$ and neutral buoyancy height in the case of co-ignimbrite clouds (see Table 2). The dashed curve also defines the distances at which the rotational and radial velocities are equal. Rotation effects are expected to be dominant to the right of this curve $\left(\mathrm{V}_{\mathrm{r}}>\mathrm{V}_{\mathrm{m}}\right)$. $\mathrm{X}$ marks the approximate conditions at which rotational effects can be observed in satellite images of the giant cloud of Mount Pinatubo in 1991 [Holasek et al., 1996]. (b) Theoretical erupted magma volume $\left(\mathrm{km}^{3}\right)$ plotted against ash cloud diameter for different stratospheric flow rates for co-ignimbrite clouds (see Table 2). 


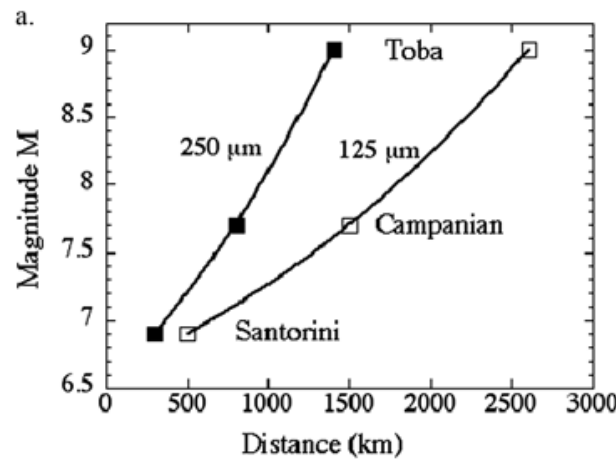

Figure 1

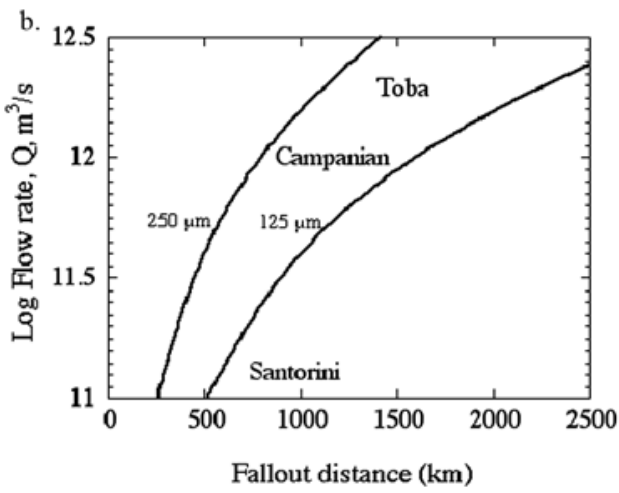

Figure 2

Figure 3. (a) The observed relationship between the eruption magnitude and distance at which the mean ash particle diameter is 250 and $125 \mu \mathrm{m}$ for Santorini, Campanian and Toba eruptions (data from Ninkovich et al. [1978]). (b) The stratospheric inflow rate is plotted against the theoretical characteristic fall-out distance, taken here as twice the e-folding distance for ash particles of 250 and $125 \mu \mathrm{m}$ (terminal velocities of 2 and $0.5 \mathrm{~m} / \mathrm{s}$ ). Assuming that this distance is approximately comparable with the distances at which the mean diameter of the ash is 250 and $125 \mu \mathrm{m}$ (shown in Figure $3 \mathrm{~b}$ ) the approximate conditions for the Santorini, Campanian and Toba eruptions are indicated.

of hundreds to thousands of kilometres in time scales of order of a day, and rotate in an anti-cyclonic manner much like a rigid body. The size of a giant cloud is limited by its volume and cyclostrophic balance, which helps to maintain its integrity against a mean stratospheric wind. This explains how these giant ash clouds can cover continent-sized areas and deposit ash over them, as has been observed from geological evidence of previous eruptions. Observations that the grain size of deposited ash increases with eruption magnitude imply that eruption intensity (i.e. flow rate) increases with eruption magnitude, a result that is consistent with the dynamic models of both Plinian and co-ignimbrite eruption columns.

[11] Acknowledgments. RSJS acknowledges support by a Royal Society Wolfson Award and PGB the support of a Visiting Professorship at Bristol University funded by the Leverhulme Trust. Herbert Huppert is thanked for helpful comments. After the completion of this work the authors became aware of the work of Ungarish and Huppert [2004], who derive some of the details of the theoretical model in a slightly different context.

\section{References}

Baines, P. G. (1995), Topographic Effects in Stratified Flows, 482 pp., Cambridge Univ. Press, New York.

Carey, S. N., and H. Sigurdsson (1989), The intensity of plinian eruptions, Bull. Volcanol., 51, 28-40.

Griffiths, R. W. (1986), Gravity currents in rotating systems, Аnпи. Rev. Fluid Mech., 18, 59-89.

Griffiths, R. W., and P. F. Linden (1981), The stability of vortices in a rotating stratified fluid, J. Fluid Mech., 105, 283-316.

Griffiths, R. W., and P. F. Linden (1985), Intermittent baroclinic instability and fluctuations in geophysical circulations, Nature, 316, 801-803.

Hallworth, M. A., H. E. Huppert, and M. Ungarish (2001), Axisymmetric gravity currents in a rotating system: Experimental and numerical investigations, J. Fluid Mech., 447, 1-29.

Holasek, R., S. Self, and A. W. Woods (1996), Satellite observations and interpretation of the 1991 Mount Pinatubo eruption plumes, J. Geophys. Res., 101, 27,635-27,655.

Koyaguchi, T. (1994), Grain-size variations of tephra derived from volcanic umbrella clouds, Bull. Volcanol., 56, 1-9.

Morton, B. R., G. I. Taylor, and J. S. Turner (1956), Turbulent gravitational convection from maintained and instantaneous sources, Proc. R. Soc. London, 234, 1-23.

Ninkovich, D., R. S. J. Sparks, and M. T. Ledbetter (1978), The exceptional magnitude and intensity of the Toba eruption, Sumatra: An example of the use of deep-sea tephra layers as a geological tool, Bull. Volcanol., 41, $1-13$.

Sparks, R. S. J., and G. P. L. Walker (1977), The significance of vitricenriched air-fall ashes associated with crystal-enriched ignimbrites, J. Volcanol. Geotherm. Res., 2, 329-341.

Sparks, R. S. J., S. N. Carey, and H. Sigurdsson (1991), Sedimentation from gravity currents generated by turbulent plumes, Sedimentology, 38, 839856.

Sparks, R. S. J., et al. (1997), Volcanic Plumes, 557 pp., John Wiley, Hoboken, N. J.

Ungarish, M., and H. Huppert (1998), The effects of rotation on axisymmetric particle-driven gravity currents, J. Fluid Mech., 362, 17-51.

Ungarish, M., and H. Huppert (2004), On gravity currents propagating at the base of a stratified ambient: Effects of geometrical constraints and rotation, J. Fluid Mech., 521, 69-104.

Ungarish, M., and T. Zemach (2003), On axisymmetric rotating gravity currents: Two-layer shallow-water and numerical solutions, J. Fluid Mech., 481, 37-66.

Woods, A. W. (1988), The fluid dynamics and thermodynamics of eruption columns, Bull. Volcanol., 50, 169-191.

Woods, A. W., and J. Kienle (1994), The dynamics and thermodynamics of volcanic clouds: Theory and observations from the April 15 and April 21, 1990 eruptions of Redoubt volcano, Alaska, J. Volcanol. Geotherm. Res., $62,273-299$.

P. G. Baines, Department of Civil and Environmental Engineering, University of Melbourne, Melbourne, Vic 3010, Australia. (pbaines@ unimelb.edu.au)

R. S. J. Sparks, Department of Earth Sciences, University of Bristol, Bristol BS8 1RJ, UK. 